\title{
ARQUITETURA ESCOLAR, CONDIÇÕES TÉRMICAS E ENSINO-APRENDIZAGEM: Análises e Reflexões
}

\author{
Emanuel Lindemberg Silva Albuquerque ${ }^{1}$ \\ Luciano Mascarenhas da Silva Sousa²
}

\begin{abstract}
RESUMO
O presente artigo visa a analisar, do ponto de vista arquitetônico, a estrutura física da unidade escolar Professor Joca Vieira, localizada no município de Teresina, Estado do Piauí, considerando suas adequações quanto às condições relacionadas ao conforto térmico, associado ao processo de ensino/aprendizagem. Neste aspecto, foi necessária a observação do ambiente físico da escola e o comportamento dos alunos em sala de aula, nos corredores, no pátio, no refeitório e na quadra de esportes. O método dialético foi o viés delineador da pesquisa em epígrafe, tendo em vista que este método consiste em abordar, de maneira dialética, as condições do ensino/aprendizagem dos alunos no ambiente escolar. A utilização da pesquisa bibliográfica permitiu elaborar o referencial teórico, associado à pesquisa de campo, no intuito de coletar dados por meio da aplicação de questionário, além de levantamento fotográfico. Ressalta-se que as instalações da referida escola estão parcialmente adequadas ao microclima local, mas há a necessidade de se analisar outros aspectos estruturais da unidade escolar, no intuito de potencializar o bom desempenho dos alunos durante todo o ano letivo.
\end{abstract}

Palavras-chave: Arquitetura escolar. Conforto térmico. Ensino/aprendizagem.

\section{SCHOOL ARCHITECTURE, THERMAL CONDITIONS AND TEACHING-LEARNING: ANALYSIS AND REFLECTIONS} \begin{abstract}
The present article aims to analyze, from the architectural point of view, the physical structure of the Joca Vieira State School Teacher, located in the city of Teresina, Piauí state, considering its adequations regarding its thermal comfort conditions, associated with the teaching/learning process. In this aspect, it was necessary to observe the physical environment of the school, the behavior of students in the classroom, in the corridors, in the courtyard, in the cafeteria and in the sports court. The dialectical method was the effluent bias of the research in the epigraph, considering that this method consists of approaching the teaching/learning conditions of the students in the school environment. The use of the bibliography research allowed to elaborate the theoretical background, associated to the use of the field research, in order to collect data through the application of questionnaire, besides the use of photographic survey. It should be highlighted that the facilities of this school are partially adequate to the local microclimate, but there is a need to analyze other structural aspects of the school unit, in order to enhance the good performance of students throughout the school year.
\end{abstract}

Keywords: School architecture. Thermal comfort. Teaching/learning.

RECEBIDO EM: $13 / 3 / 2018$

ACEITO EM: 25/6/2018

\footnotetext{
${ }^{1}$ Professor do curso de Geografia (CGEO/CCHL) e do Programa de Pós-Graduação em Geografia (PPGGEO/CCHL) da Universidade Federal do Piauí (UFPI). Membro Titular do Comitê Interno de Assessoramento Técnico-Científico da Pró-Reitoria de Pesquisa e Inovação - Propesqi/ UFPI, na área de Geografia. Coordenador da Área de Geografia do Programa Institucional de Bolsa de Iniciação à Docência - Pibid/Ufpi. Doutor em Geografia pelo Programa de Pós-Graduação em Geografia (ProPGeo) da Universidade Estadual do Ceará (Uece). Mestre em Geografia. Especialista em Geoprocessamento e Graduado em Geografia pela Uece. Líder do Grupo de Pesquisa cadastrado no CNPq intitulado: Grupo de Estudos em Geotecnologias: Pesquisa e Ensino (UFPI). Subcoordenador do Laboratório de Geografia e Estudos Ambientais - Geoambiente/UFPI. http://lattes.cnpq.br/5859482470227942. Orcid: https://orcid.org/0000-0003-3051-3301. lindemberg@ufpi.edu.br

${ }^{2}$ Graduado em Licenciatura em Geografia pela Universidade Federal do Piauí - Ufpi. Especialista em Geografia e Ensino pela Universidade Estadual do Piauí - Uespi. http://lattes.cnpq.br/5831510929434727. Orcid: https://orcid.org/0000-0003-0403-7145. lucianomascarenhas.ufpi@gmail.com
} 
A importância da pesquisa em pauta aborda como o ensino/aprendizado desenvolvido na escola é dependente de várias condições, tanto interna quanto externa. Ou seja, encontram-se condicionadas às práticas pedagógicas e em associação às questões relacionadas às estruturas físicas das unidades escolares.

A falta de informações pormenorizadas do microclima, da vegetação do entorno e da localização dos projetos arquitetônicos escolares no Piauí e, particularmente, no município de Teresina, capital do Estado, tende a influenciar na baixa climatização e qualidade dos prédios escolares construídos, o que acaba afetando o ensino nesses estabelecimentos educacionais, sendo necessária uma nova abordagem sobre essa realidade.

Neste sentido, é de importância significativa o desenvolvimento de edificações de ensino com qualidade física nos seus aspectos de conforto térmico para a comunidade escolar, devendo ser analisado o ambiente de entorno e o microclima local para a construção de prédios com maior climatização e conforto térmico para o público em pauta: alunos e professores (KOWALTOWSKI, 2011).

A realização do estudo nesta linha de pesquisa contribui para novas interpretações nos espaços de ensino/aprendizagem na cidade, a exemplo das escolas públicas. Destarte, este trabalho objetiva analisar a arquitetura da unidade escolar Professor Joca Vieira em Teresina (PI), compreendendo sua estrutura física quanto à influência do microclima local na climatização e conforto térmico, em associação ao desempenho do ensino/aprendizagem. Pautado no objetivo geral, tem-se os seguintes objetivos específicos: (a) abordar de forma integrada a educação e o processo de ensino/aprendizagem e; (b) avaliar o ambiente interno e externo da Escola Estadual Professor Joca Vieira.

Nesse sentido, o problema motivador do presente estudo parte da perspectiva de apresentar e compreender quais os aspectos das condições térmicas locais que devem ser analisados na estrutura física da escola, e qual sua influência no processo de ensino-aprendizagem dos alunos.

Em termos metodológicos, optou-se pelo método dialético, que consiste em abordar as condições de ensino-aprendizagem dos alunos ante as condições do microclima local e a climatização no conforto térmico nos ambientes interno e externo da unidade escolar ora em estudo, por meio da pesquisa in loco.

Fez-se uso ainda da pesquisa exploratória, posto que "esse tipo de pesquisa envolve o levantamento bibliográfico e a coleta de dados com pessoas que tiveram experiências práticas com o problema pesquisado" (GIL, 1991, p. 21). Foram, portanto, aplicados questionários, com perguntas abertas, aos alunos do 10 ano do Ensino Médio nos turnos manhã e tarde, bem como aos professores de ambos os turnos. Além da pesquisa de campo na unidade escolar, foi realizada visita técnica na Secretaria Estadual de Educação, particularmente no setor de engenharia/arquitetura, no intuito de coletar dados e obter informações necessárias à elucidação da problemática apresentada na pesquisa.

Vale salientar que a educação é direito de todos, e o papel do Estado é ofertá-la gratuitamente, com qualidade em escolas públicas, com ambiente adequado e com professores qualificados para o bom desempenho do aluno, o que condiz com um dos princípios da Constituição Brasileira (BRASIL, 1988). Quanto às situações físicas das escolas 
públicas estaduais em Teresina (Piauí), constatam-se, a priori, condições estruturais físicas inadequadas às condições térmicas existentes, o que tente a afetar diretamente no processo de ensino/aprendizagem.

Destaca-se que os projetos arquitetônicos escolares devem ser planejados de acordo com as condições do clima local, no intuito de potencializar o bom desempenho do conforto térmico ao ensino-aprendizagem dos alunos. Desta forma, "o espaço físico da sala, sua fachada e estrutura, o jardim, as salas de aula, os corredores, enfim, toda a organização arquitetônica é importante desse determinado ambiente que educa" (BUFFA; PINTO, 2002, p. 13).

Nessa perspectiva, o estudo em análise encontra-se estruturado para além do campo técnico da análise arquitetônica do conforto térmico em edificações, e é abordado no intuito de enriquecer a temática da arquitetura escolar no Estado do Piauí perante as suas características climáticas.

\section{EDUCAÇÃO E SUAS DIRETRIZES: Fins, Objetivos, Análises e Reflexões}

A Lei de Diretrizes e Bases da Educação Brasileira (LDB) reforça que a educação, além de ser um direito e papel do Estado, também é responsabilidade da família, por proporcionar educação, mas uma educação de cunho social, de conhecimento de mundo adquirido no meio familiar (BRASIL, 1996). Apesar de o Estado intervir na educação com aplicação de recursos e manutenção das escolas, esses recursos são administrados de forma descentralizados (União, Estados e Municípios).

Quanto às situações físicas das escolas públicas estaduais no município de Teresina (PI), a maioria apresenta, a priori, condições estruturais inadequadas, tais como salas de aulas desconfortáveis, mal iluminadas, com pouca ventilação e climatização, e seus projetos arquitetônicos não atendem, de forma integral, as condições de conforto térmico aos seus usuários (alunos e professores), tal como na unidade escolar Professor Joca Vieira, recorte espacial adotado no presente estudo.

É em consequência destas e de tantas outras reflexões que pautam a educação, que o viés do processo de ensino/aprendizagem não é alcançado de forma totalizante, tendo em vista que:

A educação deveria ser atendida com maior interesse, recebendo mais recursos para melhorar a qualidade de ensino, pois uma escola mais completa seria um incentivo para o aluno frequentá-la, diminuindo a evasão e melhorando o processo de ensino-aprendizagem, sendo que o desinteresse dos alunos é a maior causa do fracasso escolar (NUNES, 2004, p. 159).

Vale salientar que a educação é de fundamental importância para todos, sendo o processo de formação social e de transformação cultural entendido como agente emancipador, que, por meio das práticas didáticas, conduz o cidadão a compreender e desenvolver, de maneira consciente, suas relações no espaço geográfico de forma integrada, condizente com a escola cidadã. 
Neste sentido, alteram-se as formas da relação entre o Estado e a educação escolar, que supera a ideia de um Estado educador que se rege pelo princípio da igualdade de oportunidades, cuja meta é a da escola para todos, visando a proporcionar uma educação meritocrática e de pendor democrático (PADILHA, 2004).

Essa abordagem sobre a educação vai interferir, principalmente, nos conteúdos disciplinares ensinados tanto na educação infantil quanto na educação básica. Destaca-se que o ensino, como metodologia de apresentar os conteúdos, e a aprendizagem como assimilação dos conteúdos ensinados, são duas dimensões educacionais que não se separam, portanto não há ensino sem aprendizagem, uma vez que "[...] Ensinar inexiste sem aprender e vice-versa" (FREIRE, 2011, p. 26).

Há, portanto, no processo de ensino/aprendizagem a relação professor e aluno, em que o professor é responsável por ofertar conhecimento e o aluno por absorver ou assimilar os conteúdos abordados, havendo, constantemente, uma troca de experiência entre ambos. Em síntese, é um processo pedagógico que visa, através das técnicas da didática, a trazer para o aluno a interiorização reflexiva para o seu comportamento diante da realidade presente e vivenciada nos conteúdos que são trabalhados no ambiente escolar.

Como alicerce a esta ideia, Tomita (2012) afirma que a tarefa de ensinar ganha vulto e sentido pela possibilidade de apreensão da realidade sob o ponto de vista da especialidade complexa, entendendo o espaço como produto das práticas espaciais no/ do cotidiano. No exercício dessa tarefa, desenvolve-se a capacidade de leitura crítica do mundo, o que favorece a prática da cidadania numa ótica ambiental e social, ou seja, pautada na relação sociedade e natureza.

Diante desse cenário, propõem-se alternativas de ensino fora do contexto tradicional da sala de aula. Neste sentido, o ensino vai além das quatro paredes do ambiente escolar, podendo ultrapassar os limites da escola propriamente dita, tornando-o, às vezes, mais interessante e perceptível de assimilação de seus conteúdos para os alunos.

Ao considerar que "[...] O espaço geográfico é entendido como fruto do trabalho humano pela sobrevivência, onde nessa luta o homem constrói, destrói, modifica a si e a natureza" (KAERCHER, 1998, p. 20), é que essa situação fez com que o homem compreendesse o mundo em suas vicissitudes.

É nesta perspectiva que o estudo vai abordar como forma de ensino as relações vividas pelos alunos no dia a dia, desenvolvendo habilidades de análise de sua realidade presente, conduzindo-os a entender o mundo e suas relações sociais. A partir dessas tendências, o conhecimento tende a subsidiar o enriquecimento pedagógico no processo de ensino/aprendizagem.

Diante do que foi apresentado, é de fundamental importância que estes conhecimentos sejam trabalhados com profundidade e propriedade em sala de aula, pois, além do professor, é evidente que a escola possua condições infraestruturais que possibilite ao aluno manter certo nível de concentração ao conteúdo que está sendo exposto. Para tal, tem-se como recorte espacial adotado na pesquisa a unidade escolar Professor Joca Vieira, localizada no município de Teresina, Estado do Piauí. 


\section{MATERIAL E MÉTODO}

Ao considerar que a educação é de fundamental importância para todos, sendo compreendida como um processo de formação social e transformação cultural, deve ser também entendida como um agente emancipador, que, por meio das práticas didáticas, conduz o cidadão a compreender e desenvolver relações no espaço (NUNES, 2004).

Por sua vez, o ensino está presente neste contexto, tendo em vista que os conteúdos e sua metodologia são voltados aos princípios da compreensão, "atendendo as diferenças, aos interesses e às necessidades das diversas clientelas, considerando o desenvolvimento intelectual e visando a formação de uma cidadania" (OLIVEIRA, 2002, p. 218).

Diante do exposto, e na perspectiva de alcançar os objetivos da pesquisa em epígrafe, e, ainda, no intuito de obter dados concretos sobre a situação da estrutura física do prédio da unidade escolar Professor Joca Vieira, localizada no município de Teresina (PI) quanto às condições do microclima local no processo de ensino/aprendizagem dos alunos, realizou-se a aplicação de questionário para 24 alunos do Ensino Médio da referida escola, sendo 12 do turno manhã e 12 do turno tarde, seguido também da aplicação de questionários para 2 professores que lecionam nas respectivas turmas mencionadas.

Destaca-se que foi realizada uma entrevista com uma arquiteta com conhecimento em arquitetura/ambiente térmico, que fez suas observações técnicas mediante as imagens fotográficas da escola e cruzando com a planta baixa (desenho técnico) da supracitada unidade escolar, contribuindo, assim, para o enriquecimento e delineamento dos objetivos do trabalho em pauta.

Utilizou-se o software Analysis SOL-AR (disponível em: http://www.labeee.ufsc. $\mathrm{br} /$ downloads/softwares/analysis-sol-ar) para obter a carta solar da latitude da unidade escolar. Menciona-se que este é um programa gráfico que permite e auxilia nos projetos de proteções solares por intermédio da visualização gráfica dos ângulos de projeção desejados sobre transferidor de ângulos, podendo ser plotado para qualquer ângulo de orientação.

Quanto ao questionário direcionado aos alunos e aos professores, têm-se as seguintes questões: i) $\mathrm{O}$ que acha da escola em relação ao calor de Teresina (PI)? ii) Sobre a sala de aula, este ambiente ajuda no desempenho dos conteúdos ensinados pelo professor? iii) A escola oferece condições de conforto térmico ante os índices de temperatura da cidade? iv) Os espaços livres (corredores, pátio, refeitório, quadra de esportes) são ambientes ventilados e agradáveis? v) Que sugestões indicariam para a melhoria das condições de conforto térmico e para o desempenho da aprendizagem em sala de aula?

Na perspectiva de avaliar, do ponto de vista técnico, o ambiente interno e externo da Escola Estadual Professor Joca Vieira, em Teresina (PI), foram estruturadas seis perguntas direcionada a um profissional de arquitetura. Para tanto, pediu-se à arquiteta que, a partir da observação da planta baixa e das imagens da escola, apresentasse seu ponto de vista em relação às seguintes questões: i) As salas de aula estão estabelecidas de forma a proporcionar conforto térmico? ii) A localização e o posicionamento da escola encontram-se de forma adequada a proporcionar conforto térmico aos professores e alunos? iii) Os espaços livres existentes na escola oferecem condições de conforto térmico aos alunos? iv) A estrutura física do prédio escolar proporciona conforto térmico 
nos ambientes interno e externo? v) A arquitetura da escola está adequada às condições de temperatura de Teresina (PI)? vi) Que alternativa você indicaria para melhoria das condições de conforto térmico e para o aproveitamento do desempenho do ensino/ aprendizagem em sala de aula, tanto dos professores quanto dos alunos?

Diante destes questionamentos, o estudo visa a analisar o projeto arquitetônico da unidade escolar Professor Joca Vieira em Teresina (PI), e seus reflexos no processo de ensino/aprendizagem. Corrobora-se que todas as informações foram analisadas pelo escopo do método dialético, considerando a realidade presente e materializada na escola e suas confrontações diante dos diversos cenários vivenciados in loco. Destaca-se que o público-alvo da pesquisa assinou o termo de consentimento do estudo.

\section{ARQUITETURA ESCOLAR, CONDIÇÕES TÉRMICAS E ENSINO-APRENDIZAGEM: \\ A Unidade Escolar Professor Joca Vieira em Destaque}

A unidade escolar Professor Joca Vieira (Figura 1), localizada na zona leste do município de Teresina (PI), código Inep 22027327, gerida pela Secretaria Estadual de Educação, tem horário de funcionamento nos turnos manhã e tarde e atende ao público escolar do Ensino Médio. A referida escola é constituída de 27 compartimentos, entre salas de aula, sala dos professores, pátio, refeitório e quadra de esporte, conforme é apresentado na Figura 2.

Figura 1 - Mapa de localização da unidade escolar Professor Joca Vieira, município de Teresina, Estado do Piauí
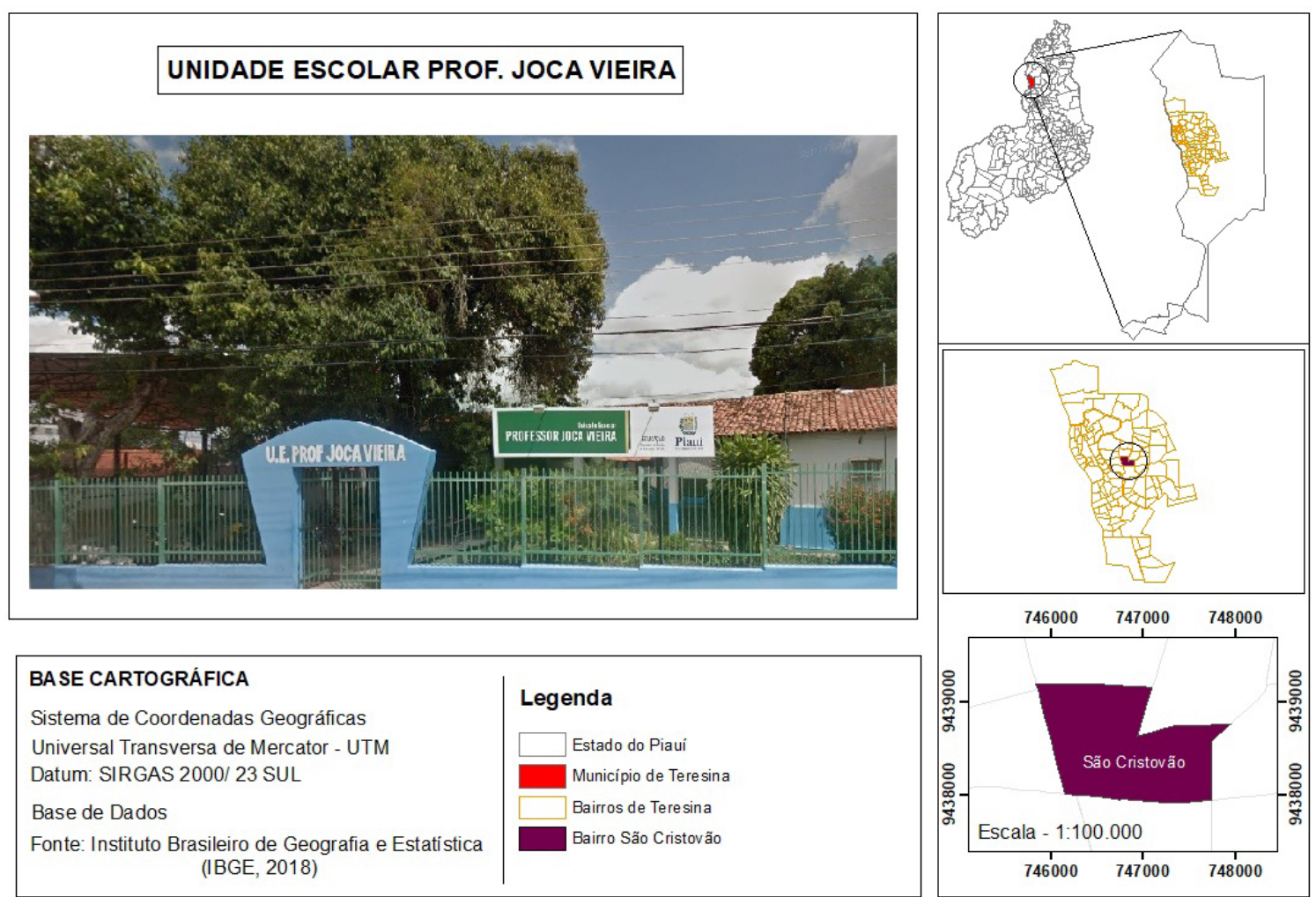

Fonte: Elaborada pelos autores (2018). 
Figura 2 - Planta baixa da unidade escolar Professor Joca Vieira, Teresina, Piauí

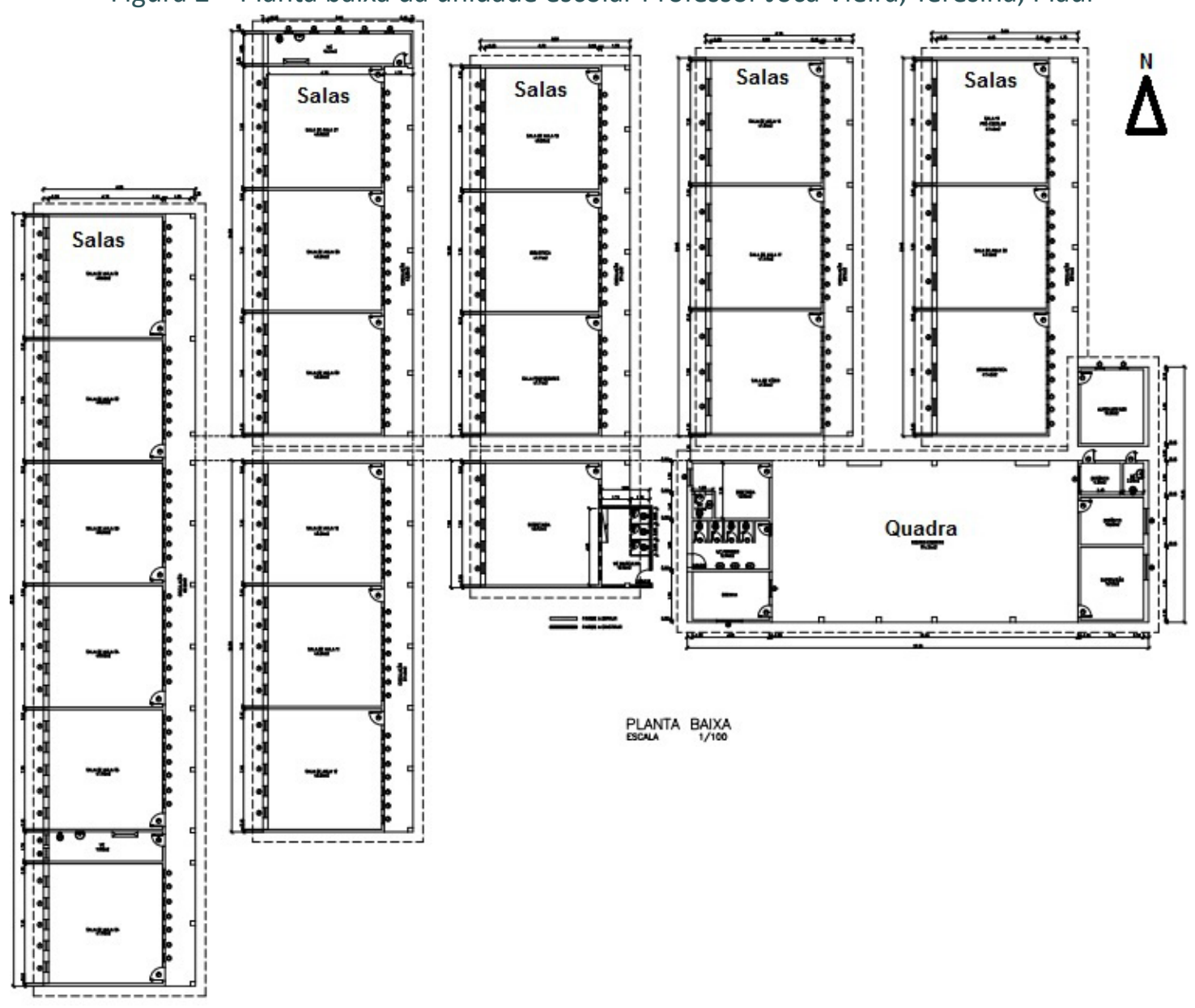

Fonte: PIAUÍ, 2017.

Construída no sentido vertical (norte/sul) no perfil de blocos de salas, é favorável à penetração em seus compartimentos de brisas vindas de orientação leste, sendo constatada a incidência solar no período da manhã e da tarde em virtude da posição de sua construção. Para determinar a insolação, utilizou-se o software SOL-AR, a fim de verificar as fachadas que tendem a receber uma maior incidência de raios solares durante o ano e as mais protegidas. Para isso, foram orientadas de acordo com a angulação em relação ao norte verdadeiro. A fachada Sudeste (orientada a $109^{\circ}$, em relação ao norte verdadeiro) recebe sol de janeiro a junho no período da manhã. Por outro lado, a fachada Noroeste (orientada a $291^{\circ}$, em relação ao norte verdadeiro) recebe sol de junho a dezembro, no período da tarde, conforme é apresentado na Figura 3. 
Figura 3 - Carta solar das fachadas de sudeste e noroeste da unidade escolar Professor Joca Vieira, município de Teresina, Estado do Piauí
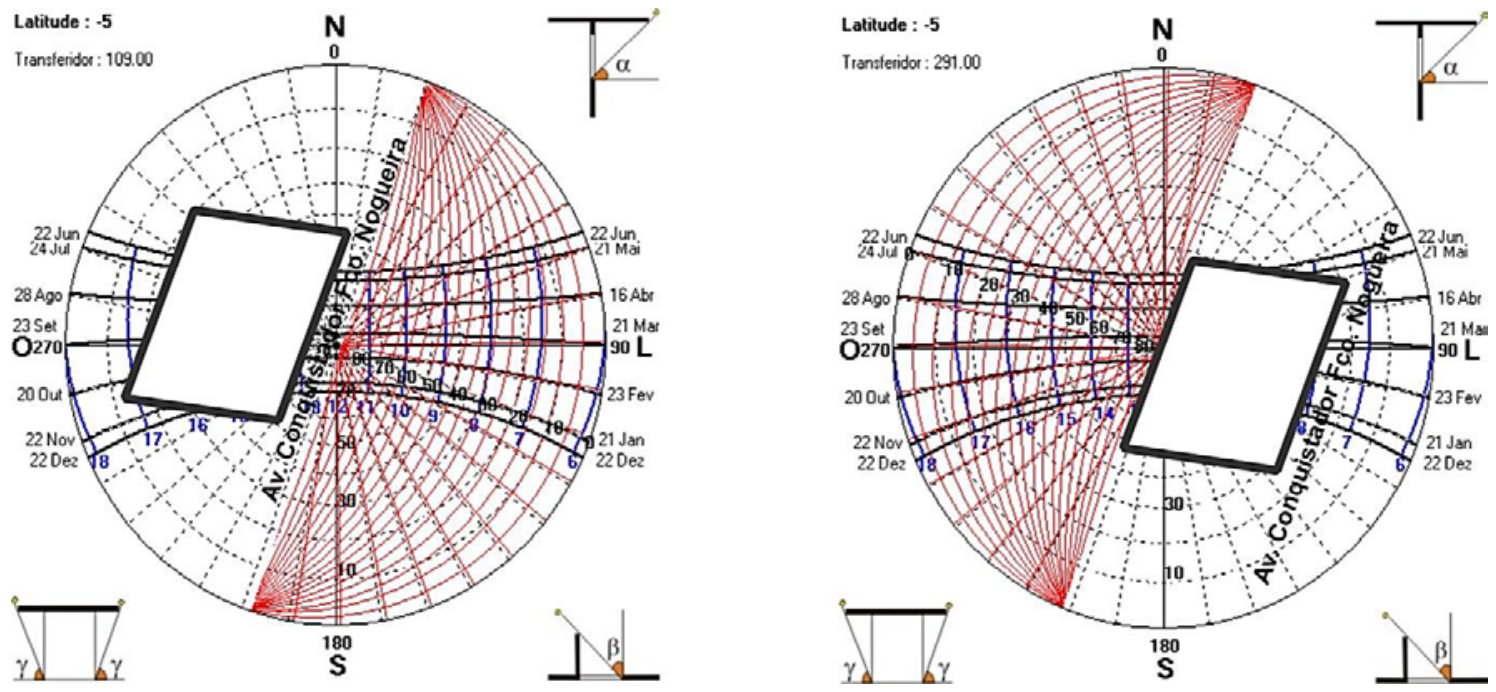

Fonte: Elaborada pelos autores (2018).

Não há praça ou qualquer ambiente que auxilie no conforto térmico. É uma região caracterizada como ilha de calor latente. No ambiente interno, ou seja, nas salas de aula, suas condições físicas estão apropriadamente bem-conservadas. A posição das janelas nas laterais dos blocos permite a iluminação natural. A iluminação artificial, por sua vez, não favorece o interior das salas de aula.

É aconselhável que a Secretaria de Educação do Estado, em parceria com a gestão da escola e com a cooperação dos professores e alunos, desenvolva projeto de arborização da escola com plantas nativas. Desta maneira, tende a surgir no ambiente interno e externo da escola microclima com condições térmicas mais agradáveis, amenizando o forte calor derivado da ilha de calor que perdura nas imediações da escola.

O prédio (Figura 4) está bem-conservado, posto que o comprimento das salas é adequado, necessitando de alguns equipamentos de refrigeração (Figura 5). Não obstante, a largura dos corredores, a priori, é considerada imprópria para a circulação permanente dos usuários, conforme é retratado na Figura 6.

Figura 4 - Entrada da unidade escolar Professor Joca Vieira, Teresina, Piauí

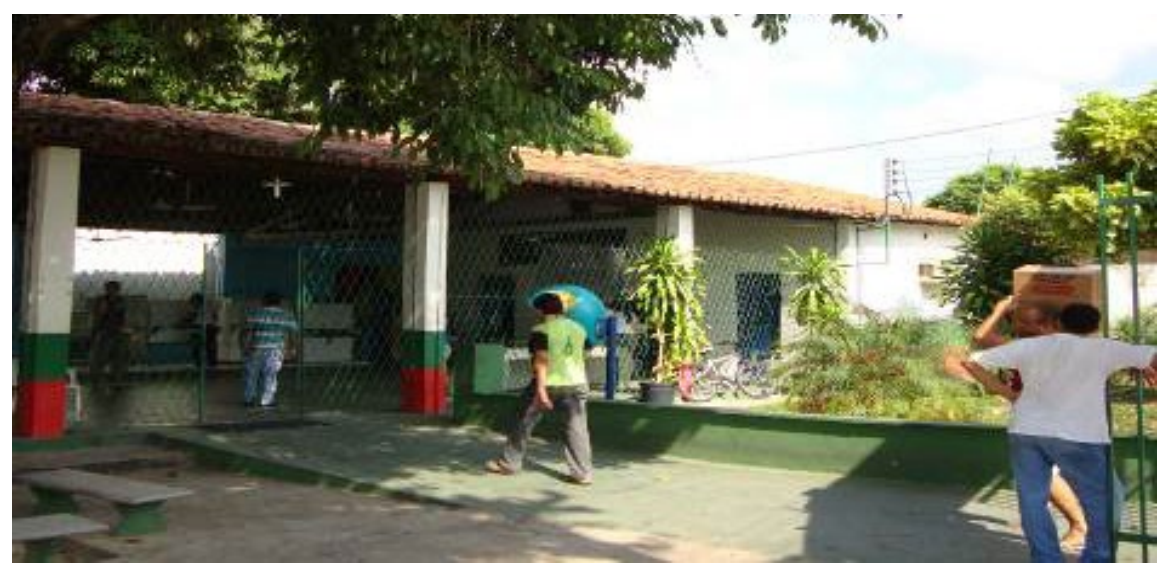

Fonte: Os autores (2017). 
Figura 5 - Sala de aula na unidade escolar Professor Joca Vieira, Teresina, Piauí

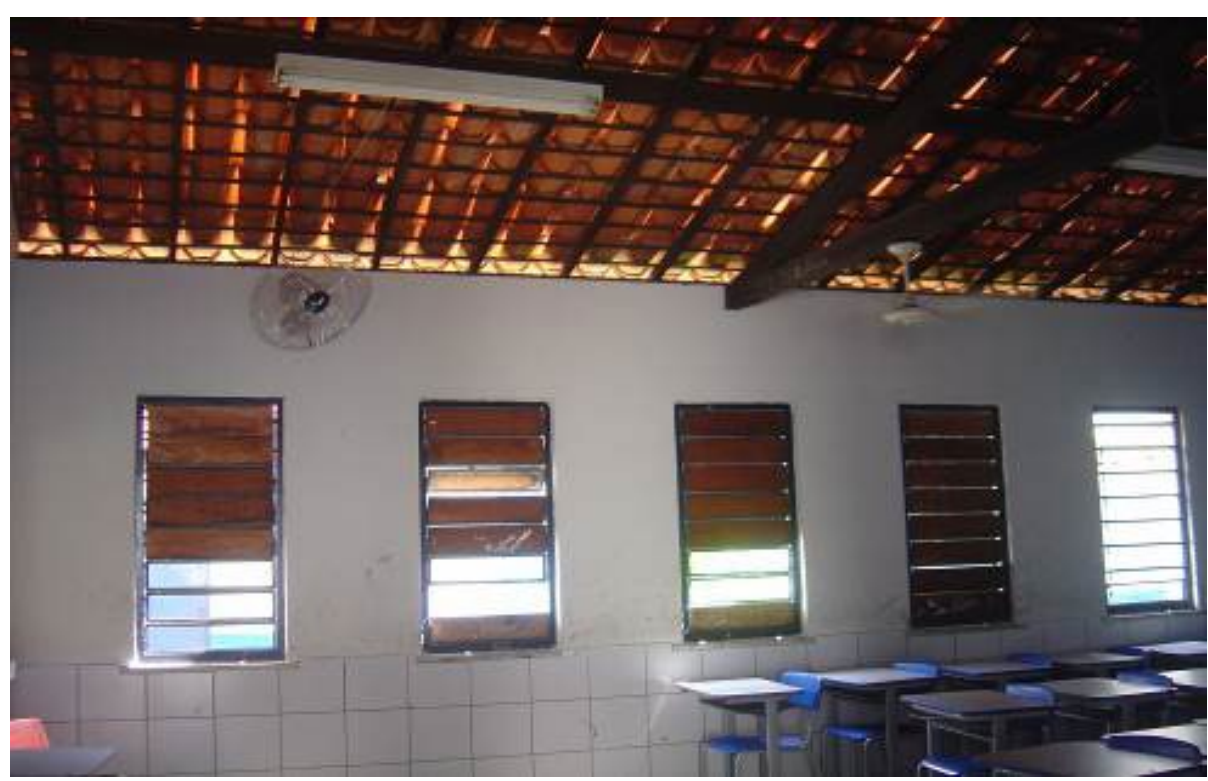

Fonte: Os autores (2017).

Ao considerar o ambiente interno das salas de aula, a posição das janelas na lateral/vertical favorece a entrada de vento dentro do ambiente, amenizando, de certo modo, o calor interno, uma vez que o sistema de ventilação é mecânico, ou seja, por meio de ventiladores.

Figura 6 - Corredor central da unidade escolar Professor Joca Vieira, município de Teresina, Estado do Piauí

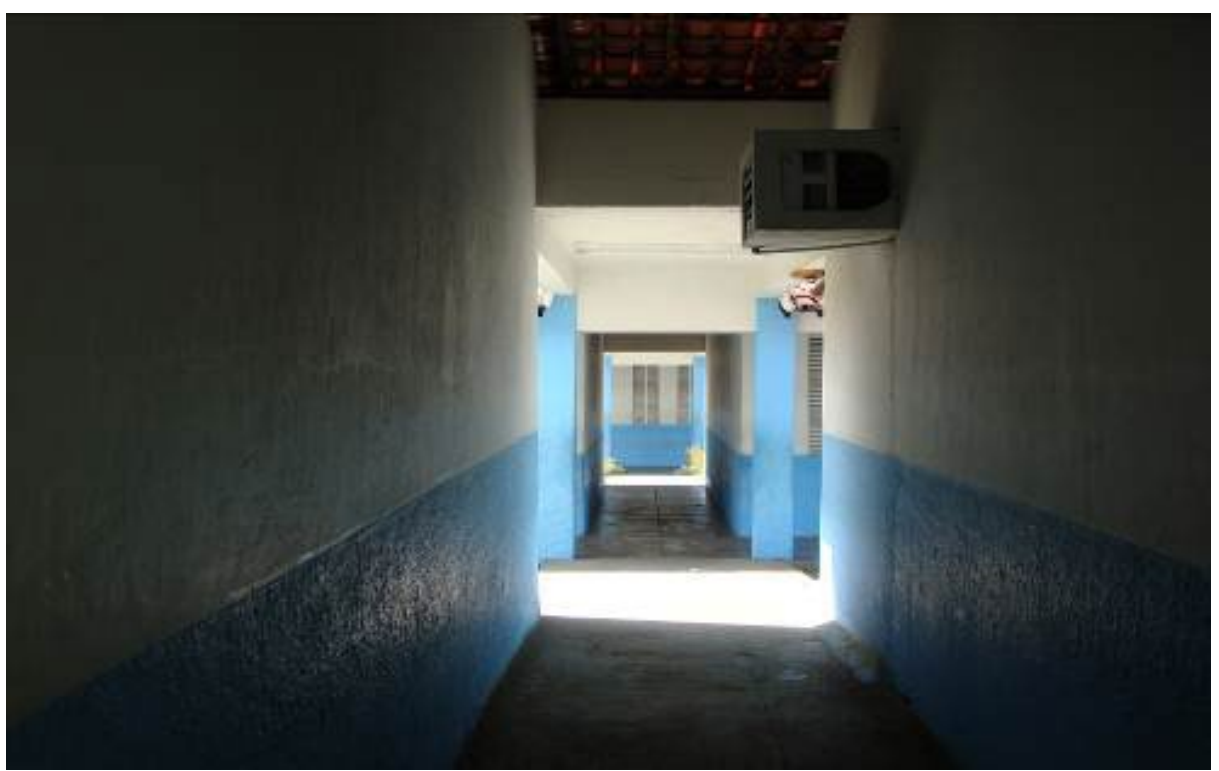

Fonte: Os autores (2017).

Não obstante, vale mencionar que o vento proveniente dos setores externos não é constante, tendo em vista as próprias características meteorológicas do município de Teresina ( $\mathrm{PI}$ ). Associado ao exposto, menciona-se que todo o perímetro urbano do en- 
torno da escola é caracterizado pela intensa pavimentação asfáltica, o que tende a potencializar a elevação da temperatura e, consequentemente, gerar o desconforto térmico no ambiente interno do prédio escolar.

Nesse sentido, a arquitetura representa, geometricamente, os projetos que norteiam a leitura para a execução de edificações. Os projetos arquitetônicos, portanto, devem contemplar o estudo preliminar das condições físicas e ambientais do espaço onde o equipamento será construído. Dessa forma, "[...] A arquitetura, ou desenho urbano, busca definir as condições ambientais, do meio natural e construído, que melhor satisfaça às exigências do conforto térmico do homem" (ROMERO, 2000, p. 12).

É oportuno que projetos arquitetônicos contribuam no conforto térmico das edificações construídas, levando em consideração o clima e o menor consumo de energia, associado às sensações térmicas encontradas em cada setor espacial, na perspectiva de que "adequar a arquitetura ao clima de um determinado local, significa construir espaços que possibilitem ao homem condições de conforto" (FROTA, 2003, p. 53).

De acordo com Romero (2000, p. 83):

Os modelos de conforto térmico, adequadamente desenvolvidos, são um instrumento importante para o estudo das técnicas de controle do ambiente, uma vez que permitem a identificação daquelas variáveis do meio que devem ser modificadas e/ou aproveitadas para se conseguirem as condições de conforto desejadas, a partir do próprio projeto de arquitetura.

É nesta percepção que os projetos arquitetônicos escolares devem ser planejados, considerando as condições do clima local e no intuito de resultar no bom desempenho do conforto térmico no processo de ensino-aprendizagem dos alunos, particularmente nas cidades com temperaturas elevadas.

Nessa perspectiva, o município de Teresina (PI) caracteriza-se por possuir clima que proporciona, naturalmente, desconforto térmico, por consequência das médias de temperatura, que oscilam de $26^{\circ} \mathrm{C}$ a $40^{\circ} \mathrm{C}$ ao longo do ano, atrelado ainda a uma umidade relativa do ar muito baixa.

Diante do exposto e dos objetivos traçados na pesquisa, associado aos questionários aplicados, considerando os procedimentos metodológicos utilizados, tem-se as seguintes respostas obtidas dos alunos:

"O que acha da escola em relação ao calor de Teresina"? Doze alunos do grupo de 24 responderam de forma negativa, colocando a escola como ruim e mal equipada; muito quente, pouco ventilada e o calor na sala é insuportável, dificultando a concentração e o entendimento dos assuntos abordados nas aulas.

Na pergunta seguinte foram questionados: "Sobre a sala de aula, este ambiente ajuda no desempenho dos conteúdos ensinados pelo professor"? Dos 12 alunos do turno da manhã, 11 responderam que o ambiente da sala de aula ajuda a entender os conteúdos ensinados pelo professor de forma parcial, tendo em vista que o calor não é tão intenso até às $9 \mathrm{~h} 30 \mathrm{~min}$ da manhã, e, após esse horário, a sala de aula torna-se quente e não ajuda no desempenho dos alunos quanto aos conteúdos ensinados. Apenas 1 aluno do turno da manhã respondeu que o ambiente da sala de aula ajuda a entender os conteúdos ensinados independentemente de horário. Os 12 alunos do turno da tarde, 
de modo geral, afirmaram que o ambiente da sala de aula não ajuda, pois o calor tira a atenção do que o professor está ensinando, e o ambiente da sala de aula é quente e abafado.

Perguntou-se também: "A escola oferece condições de conforto térmico ante os índices de temperatura da cidade"? Os 24 alunos, de ambos os turnos, responderam que oferece condições de conforto térmico de maneira parcial, por meio da utilização insuficiente de ventiladores, tendo em vista que apenas nas salas do 20 e 30 anos do Ensino Médio, nas salas dos professores e na Secretaria há climatização por ar-condicionado. As salas de aula e os demais setores, como refeitório e corredores, são quentes e desagradáveis.

Questionou-se ainda aos alunos: "Os espaços livres (corredores, pátio, refeitório, quadra de esportes) são ambientes ventilados e agradáveis"? Todos os 24 alunos responderam de forma negativa, considerando esses espaços como quentes, pouco ventilados, pequenos para o número de pessoas e ainda citaram que a quadra de esportes não é coberta, o que aumenta mais o desconforto térmico quando da utilização deste ambiente pela comunidade escolar.

Por fim, indagou-se aos alunos: "Que sugestões indicariam para a melhoria das condições de conforto térmico para o desempenho da aprendizagem em sala de aula"? Esta foi a última questão feita aos alunos, que sugeriram, de forma unânime, a colocação de ar-condicionado em todas as salas de aulas.

O outro questionário foi direcionado para dois professores que atuam em turnos diferentes na escola. Inicialmente perguntou-se o seguinte: "O que acha da escola em relação ao calor de Teresina"? O professor do turno manhã considerou a arquitetura da escola não adequada às condições climáticas da cidade, enquanto o professor do turno da tarde a considera razoável, em razão de a escola possuir algumas salas com ar-condicionado.

Perguntou-se: "Sobre a sala de aula, este ambiente ajuda no desempenho dos conteúdos ensinados para os alunos"? Os dois docentes responderam negativamente, pois, pelo calor, os alunos não conseguem se concentrar e saem constantemente da sala de aula. Informaram ainda que há falta de recursos para a melhoria dos ventiladores, compra de ar-condicionado, construção de teto novo e forrado, e, para estes, as melhorias citadas ajudariam no ambiente da sala de aula e diretamente influenciariam no bom desempenho dos alunos em relação aos conteúdos ensinados.

Foi perguntado também: "A escola oferece condições de conforto térmico ante os índices de temperatura da cidade"? Os dois professores responderam que a escola não oferece nenhuma condição.

Na pergunta seguinte, buscou-se saber: "Os espaços livres (corredores, pátio, refeitório e quadra de esportes) são ambientes ventilados e agradáveis"? Os professores consideram que são bem-ventilados e agradáveis. A resposta dos docentes difere da resposta apresentada pelos alunos, pois estes disseram que estes espaços são quentes, pouco ventilados, pequenos para o número de pessoas, além de uma quadra de es- 
porte sem cobertura. Nesse sentido, questiona-se: Será que os professores frequentam realmente esses espaços livres ou ficam somente na sala climatizada destinada a eles, não conhecendo a realidade desses espaços livres?

Solicitou-se também aos docentes, em forma de pergunta: "Que sugestões indicaria para a melhoria das condições de conforto térmico para o desempenho da aprendizagem em sala de aula"? O professor do turno manhã propôs a climatização de todas as salas de aula. O professor do turno tarde sugeriu a colocação de aspersores no telhado para o resfriamento do teto, o que tenderia a diminuir a temperatura no ambiente interno da sala de aula.

Outro ponto relevante para o trabalho em destaque foi a riqueza de informações obtidas com uma profissional da área de arquitetura, especialista em arquitetura e conforto térmico. Foram feitas seis perguntas para a mesma. Solicitou-se à arquiteta que, a partir da observação da planta baixa e das imagens (fotografias) da escola, apresentasse seu ponto de vista técnico em relação aos compartimentos da unidade escolar Professor Joca Vieira, em Teresina (PI).

Segue as seguintes perguntas e respostas: Os compartimentos estão estabelecidos de forma a proporcionar conforto térmico? Para a arquiteta, as salas de aula possuem aberturas em dois lados opostos, o que possibilita a ventilação cruzada, caso as janelas, basculantes de madeira/vidro, fiquem abertas. No lado oposto, os elementos vazados permitem também a saída do ar. A disposição das salas em fileira única, com corredor lateral, é ideal para permitir a ventilação cruzada e, consequentemente, proporcionar conforto térmico.

Foi perguntado sobre a localização e posicionamento da escola, no intuito de saber: A mesma encontra-se de forma adequada a proporcionar conforto térmico aos professores e alunos? Para ela, em relação ao posicionamento dos blocos eles estão dispostos com o eixo maior leste/oeste e as aberturas para o norte/sul, o que é a situação ideal para Teresina, permitindo a entrada da ventilação predominante de sudeste. A proximidade entre os blocos, entretanto, prejudica a ventilação das salas, porque um bloco faz barreira à passagem da ventilação para o bloco seguinte.

Indagou-se para a arquiteta sobre os espaços livres existentes na escola: Os mesmos oferecem condições de conforto térmico aos alunos? O pátio coberto é aberto no lado leste, permitindo a entrada da ventilação. $O$ fato da cobertura não ter forro, contudo, compromete o conforto térmico nos horários mais quentes do dia, em razão da radiação térmica emitida pelas telhas que aquecem pela radiação solar. $\mathrm{Na}$ entrada da escola as árvores altas permitem o sombreamento da área externa e criam um microclima mais agradável.

Perguntou-se ainda: A estrutura física do prédio escolar proporciona conforto térmico nos ambientes interno e externo? Segundo ela, a cobertura das salas de aula não possui forro, o que não é recomendado para as características climáticas de Teresina, pelo aquecimento das telhas e a radiação térmica emitida durante o dia. Destaca-se que os ventos não chegam a todas as salas em virtude da proximidade entre os blocos. 
Foi questionado também: A escola está adequada às condições de temperatura de Teresina? A arquiteta afirmou que, apesar de o projeto da escola atender a alguns requisitos necessários para proporcionar conforto térmico em sala de aula sem climatização artificial, como eram todas as escolas estaduais e municipais em Teresina num passado recente, esta escola não está totalmente adequada às condições climáticas da capital piauiense, principalmente durante o 20 (segundo) semestre do ano, quando ocorrem as temperaturas médias mais elevadas e a umidade relativa do ar fica mais baixa.

Perguntou-se: Indicaria alguma alternativa para a melhoria das condições de conforto térmico para o aproveitamento do desempenho do ensino/aprendizagem em sala de aula, tanto por parte dos alunos, quanto dos professores? Em relação às salas de aula, para a arquiteta, a existência de forro contribuiria para diminuir a radiação térmica emitida pelas telhas e que aquecem o ambiente interno e aumentam, consequentemente, a temperatura do ar. As áreas externas sombreadas por árvores de copa alta (que não barrem a ventilação) ou pergolados, que também ajudem a sombrear estas áreas, poderão criar um microclima no entorno dos blocos, contribuindo para diminuir a temperatura do ar e aumentar a umidade relativa. Nas salas de aula a principal fonte de calor são as próprias pessoas e, em locais de clima quente como em Teresina (PI), a ventilação destes espaços é extremamente necessária para retirar o excesso de calor, melhorando a sensação de conforto térmico nas pessoas.

Ao considerar as respostas obtidas dos alunos, professores e da arquiteta, todos, direta e/ou indiretamente, reprovaram, de forma parcial, as condições estruturais e físicas do prédio da unidade escolar Professor Joca Vieira em Teresina (PI), considerando as condições do microclima local perante o processo de ensino/aprendizagem.

Em virtude dessas características é que os projetos arquitetônicos, principalmente dos prédios escolares, devem ser projetados e/ou reprojetados para amenizar essas condições climáticas adversas durante o período letivo. Neste sentido, o projeto arquitetônico bioclimático surge como uma alternativa para suprir estas particularidades climáticas, tendo em vista que este objetiva prover um ambiente construído com conforto físico, sadio e agradável, adaptado ao clima local, que minimize o consumo de energia convencional com instalação da menor potência elétrica possível (CORBELLA; YANNAS, 2009).

Nesse sentido, seguindo os preceitos de Kowaltowski (2011), é imprescindível que as condições ambientais locais sejam levadas em consideração no momento de execução de um projeto arquitetônico, tendo em vista que a qualidade do ensino, do ponto de vista prático, vai além da qualificação do docente, da remuneração e do quantitativo de discentes, mas inclui neste bojo as condições infraestruturais e de confortabilidade que permeiam o ambiente escolar.

\section{CONSIDERAÇÕES FINAIS}

O presente estudo objetivou analisar a arquitetura predial da unidade escolar Professor Joca Vieira, localizada no município de Teresina (PI), compreendendo sua estrutura física quanto à influência do microclima local na climatização e conforto térmico, em associação ao desempenho do ensino/aprendizagem. 
Diante do exposto, é conveniente o estudo direcionado à arquitetura escolar, no intuito de refletir sobre as condições do microclima local quanto aos aspectos físicos dos ambientes, tanto interno quanto externo, dos prédios escolares, na perspectiva de vislumbrar um bom desempenho dos alunos durante todo o período letivo, sobretudo no 2 o semestre do ano no município de Teresina (PI), onde as temperaturas ficam bem acima da média.

O ajustamento da estrutura física das escolas para a melhoria da climatização dos espaços, no intuito de potencializar o processo de ensino/aprendizagem, é de fundamental importância, em virtude das características térmicas predominantes no recorte espacial da pesquisa, ou seja, o desconforto término em sala de aula prejudica o bom andamento dos trabalhos dos professores e não favorece o aprendizado dos alunos.

Constatou-se, diante do exposto, uma deficiência na arquitetura e estrutura física da unidade escolar Professor Joca Vieira, destacando que as salas de aulas são desconfortáveis, mal iluminadas, com pouca ventilação e climatização. Desta forma, o projeto arquitetônico da mencionada escola não atende às condições de conforto térmico de seus usuários, ou seja, de alunos e professores.

De acordo com os dados obtidos, há um consenso entre o público investigado de que a solução para o bom desempenho dos alunos no processo de ensino/aprendizagem seria a climatização artificial das salas de aulas, por meio da instalação de apareIhos de ar condicionado.

Do ponto de vista estrutural, há a necessidade de um maior espaçamento entre os blocos, na perspectiva de permitir um aumento da ventilação entre as salas, bem como a construção de um teto com altura adequada e telhado feito de material que não proporcionasse maior concentração de radiação, impedindo, assim, o aquecimento do ambiente interno da sala de aula.

Em síntese, a realidade da climatização artificial tornou-se fator predominante para a qualidade do ensino/aprendizagem nas escolas de Teresina (PI), tendo em vista que os projetos de construção dos prédios escolares são elaborados e postos em execução, muitas vezes, de maneira distorcida da realidade local ou com projetos adaptados de outras cidades, pois são executados sem levar em consideração o fator do microclima local.

Outro ponto relevante que os projetos arquitetônicos de prédios escolares deixam em segundo plano é a não utilização de recursos naturais para o favorecimento da climatização, tendo em vista que muitos dos projetos não utilizam a vegetação como recurso estratégico de amenização da temperatura, seja pela supressão vegetal ou pela pavimentação dos espaços, como é o caso da unidade escolar Professor Joca Vieira, em Teresina (PI).

\section{REFERÊNCIAS}

BRASIL. Constituição da República Federativa do Brasil. Brasília, DF: Senado Federal, 1988.

BRASIL. Lei de Diretrizes e Bases da Educação Nacional. LDB - Lei 9.394/96. 1996. Disponível em: www. planalto.gov.br. Acesso em: 25 jun. 2017. 
BRASIL. Ministério da Educação e do Desporto. Conselho Nacional de Educação. Câmara de Educação Básica. Parecer CEB n. 4/98. Diretrizes Curriculares Nacionais para o Ensino Fundamental. Brasília, DF: MEC; CNE, 1998.

BUFFA, Ester; PINTO, Gelson de Almeida. Arquitetura e educação: organização do espaço e propostas pedagógicas dos grupos escolares paulistas, 1893/1971. São Carlos, SP: EdUFScar, 2002.

CASSABI, Clarice. Reflexões sobre o ensino de geografia. Geografia: Ensino \& Pesquisa. Santa Maria, v. 13, n. 1, p. 43-50, 2009.

CORBELLA, Oscar; YANNAS, Simos. Em busca de uma arquitetura sustentável para os trópicos: conforto ambiental. 2. ed. Rio de Janeiro: Revon, 2009.

CAVALCANTI, Lana de Souza. A geografia e a realidade escolar contemporânea: avanços, caminhos, alternativos. In: SEMINÁRIO NACIONAL: CURRÍCULO EM MOVIMENTO-PERSPECTIVAS ATUAIS, 1., Belo Horizonte. Anais [...]. Belo Horizonte, 2010, p. 1-16.

CAVALCANTI, Lana de Souza. Geografia, escola e construção de conhecimento. Campinas: Papirus, 1998.

GIL, Antônio Carlos. Como elaborar projetos de pesquisa. São Paulo: Atlas, 1991.

FROTA, Anésio Barros. Manual de conforto térmico. 7. ed. São Paulo: Studio Nobel, 2003.

FREIRE, Paulo. Pedagogia da autonomia: saberes necessários à prática educativa. São Paulo: Paz e Terra, 2011.

KEARCHER, Nestor André. A geografia é o nosso dia-a-dia. Geografia em sala de aula: prática e reflexões. Porto Alegre: Ed. UFRGS, 1998.

KOWALTOWSKI, Doris Catharine Cornelie Knatz. Arquitetura escolar: o projeto do ambiente de ensino. São Paulo: Oficina de Textos, 2011.

NUNES, Adão Cícero Ferreira. As dificuldades de ensinar geografia. Geografia. Londrina, v. 13, n. 1, p. 151162, jan./jun. 2004.

OLIVEIRA, Lívia de. O ensino/aprendizagem de geografia nos diferentes níveis de ensino. In: PONTUSCHKA, Nídia Nacib (org.). Geografia em perspectiva: ensino e pesquisa. São Paulo: Contexto, 2002.

PADILHA, Paulo Roberto. Currículo intertranscultural: novos itinerários para a educação. São Paulo: Cortez: Instituto Paulo Freire, 2004.

PIAUÍ. Secretaria de Estado da Educação do Piauí. Instrução Normativa GSE/ADM n001/2017. Teresina/PI: Seduc, 2017.

ROMERO, Marta Adriana Bustos. Princípios bioclimáticos para o desenho urbano. São Paulo: ProEditores, 2000,

SILVA, Onildo Araújo da. Geografia: metodologia e técnicas de ensino. Feira de Santana/BA: Uefs, 2004. TOMITA, Luzia Mitiko Saito. Os desafios de aprender e ensinar geografia. In: ASARI, Alice Yatiyo (org.). Múltiplas geografias: ensino, pesquisa e extensão. Londrina: UEL, 2012. 